\title{
ANALISIS STRATEGI PEMANFAATAN LIMBAH TANAMAN PANGAN SEBAGAI PAKAN RUMINANSIA DI SULAWESI SELATAN
}

\author{
Jasmal A. Syamsu ${ }^{1}$ \\ Agustina Abdullah ${ }^{1}$ \\ ${ }^{1}$ Fakultas Peternakan Universitas Hasanuddin Makassar \\ E-mail: jasmals@yahoo.com
}

\begin{abstract}
Vector Auto Regression (VAR) is an analysis or statistic method which can be used to predict time series variable and to analyst dynamic impact of disturbance factor in the variable system. In addition, VAR analysis is very useful to assess the interrelationship between economic variables. This research through the following test phases: unit root test, test of hypothesis, Granger causality test, and form a vector autoregresion model (VAR). The data used in this research is the GDP data and budget data of South Sulawesi in the period 1985-2004. The research aims to analyze the interrelationship between public expenditure and economic growth in South Sulawesi. The result showed statistically significant in economic growth (PDRB) influence public expenditure (APBD), however, not vice versa. Otherwise, for the need of APBD prediction, the used of lag 4 was the optimum model based on the causal relationship to PDRB.
\end{abstract}

Key word: hubungan kausalitas, belanja publik, pertumbuhan ekonomi, Vector Auto Regression (VAR) analysis

\section{PENDAHULUAN}

Paradigma pembangunan peternakan adalah terwujudnya masyarakat yang sehat dan produktif serta kreatif melalui peternakan tangguh berbasis sumberdaya lokal. Untuk mencapai paradigma tersebut dilakukan berbagai misi yaitu (1) menyediakan pangan asal ternak, (2) memberdayakan sumberdaya manusia peternakan, (3) meningkatkan pendapatan peternakan, (4) menciptakan lapangan kerja peternakan, dan (5) melestarikan dan memanfaatkan sumberdaya alam, yang secara keseluruhannya selaras dengan program pembangunan pertanian yaitu membangun ketahanan pangan dan mengembangkan sektor agribisnis pertanian Selanjutnya pengem- bangan di bidang peternakan dilakukan melalui strategi pengembangan pilar peternakan utama yaitu pengembangan potensi ternak dan bibit ternak, pengembangan pakan ternak, serta pengembangan teknologi budidaya. Ketiga pilar utama peternakan terkait oleh sanitasi dan kesehatan ternak serta peningkatan industri dan pemasaran hasil peternakan, pengembangan kelembagaan usaha dan keterampilan peternak serta kawasan pengembangan peternakan.

Peternakan di Indonesia pada dasarnya dapat dikelompokkan dalam empat kategori yaitu (a) usaha peternakan bersifat pre industri dimana usaha bersifat subsisten, semua aktivitas dilakukan oleh peternak, hampir 
tidak ada peran organisasi pemerintah maupun swasta, (b) usaha peternakan yang mulai timbul pertimbangan industri atau bisnis. Di sini peran pemerintah dalam banyak hal cukup dominan dan hampir tidak ada industri swasta yang terlibat. Contoh usaha ini adalah peternakan kerbau, dan ayam buras, (c) usaha peternakan dalam tahap ekspansi, di mana peran pemerintah dan swasta cukup besar. Pada tahap ini peran pemerintah dalam hal penelitian dan pengembangan cukup dominan walaupun swasta sudah tertarik untuk berusaha seperti contoh pada usaha sapi perah, domba, dan itik, serta (d) usaha peternakan tahap industri yang matang, dimana peran swasta sangat dominan serta telah mampu mengembangkan penelitian dan pengembangan untuk mendukung usahanya.

Terkait dengan pengembangan pakan ternak, diarahkan untuk mengoptimalkan pemanfaatan bahan baku pakan lokal untuk mengurangi ketergantungan terhadap impor bahan baku pakan. Secara umum untuk pengembangan pakan memiliki permasalahanpermasalahan, antara lain: (a) kebutuhan bahan baku pakan tidak seluruhnya dipenuhi dari lokal sehingga masih mengandalkan impor, (b) bahan baku pakan lokal belum dimanfaatkan secara optimal, (c) ketersediaan pakan lokal tidak kontinyu dan kurang berualitas, (d) penggunaan tanaman legum sebaai sumber pakan belum optimal, (e) pemanaatan lahan tidur dan lahan integrasi masih rendah, (f) penerapan teknologi hijauan pakan masih rendah, (g) produksi pakan nasional tidak pasti akibat akurasi data yang kurang tepat, serta (h) penelitian dan aplikasinya tidak sejalan.

Pengembangan peternakan sangat terkait dengan pengembangan suatu wilayah. Sulawesi Selatan sebagai salah satu propinsi di
Indonesia memiliki potensi cukup besar dalam pengembangan peternakan. Sulawesi Selatan pernah dikenal sebagai lumbung ternak, dengan kemampuan memasok ternak ke daerah lain dalam rangka pengadaan ternak nasional (Syamsu, et al., 2003). Berbagai permasalahan dalam pembangunan peternakan di Sulawesi Selatan, adalah: (1) kecenderungan penurunan populasi khususnya sapi dan kerbau karena makin tingginya pemotongan betina produktif serta faktor keamanan juga sangat berpengaruh dimana minat sebagian peternak untuk memelihara ternak menurun, (2) skala usaha kecil, umumnya skala usaha masih terbatas pada skala usaha sambilan dan hanya sebagian kecil yang menjadikan usaha pokok dan cabang usaha sehingga untuk bersaing dengan daerah lain yang menjadikan komoditasnya sebagai usaha pokok kurang kompetitif, (3) kualitas produk peternakan masih rendah, (4) terbatasnya permodalan, (5) lemahnya kelembagaan terutama di tingkat kelompok tani dan peternak, serta (6) sumberdaya pakan khususnya hijauan untuk ternak ruminansia ketersediannya fluktuatif (Syamsu dan Achmad, 2002).

Salah satu faktor penentu keberhasilan pembangunan peternakan khususnya pengembangan ternak ruminansia di Sulawesi Selatan adalah ketersediaan sumberdaya pakan. Namun demikian, padang penggembalaan sebagai penyedia pakan hijauan cenderung berkurang setiap tahun. Luas padang penggembalaan di Sulawesi Selatan tahun 2006 adalah 235.542 ha dan mengalami penurunan jika dibandingkan tahun 2001 seluas 290.184 ha (BPS 2007). Di lain pihak, telah terjadi perubahan fungsi lahan yang sebelumnya sebagai penyedia sumber pakan menjadi lahan sawah/pertanian untuk memenuhi tuntutan penyediaan pangan akibat semakin 
meningkatnya jumlah penduduk. Di samping itu penyediaan pakan juga memiliki keterbatasan akibat adanya persaingan kebutuhan penyediaan pangan untuk konsumsi manusia.

Sulawesi Selatan dengan luas wilayah 6.248.254ha, sekitar 44,5 persen $(2.781 .310$ ha) merupakan lahan pertanian, dan dari lahan pertanian ini sekitar 598.216ha adalah lahan persawahan. Peningkatan luas lahan pertanian memberikan implikasi terhadap peningkatan luas areal panen tanaman pangan. Tahun 2006, di Sulawesi Selatan luas areal panen padi seluas 847.305 ha atau 6.85 persen dari luas areal panen di Indonesia, dan luas areal panen jagung, kedelai, kacang tanah, ubi kayu dan ubi jalar masing-masing 6.91 persen, 3.97 persen, 6.13 persen, 3.53 persen dan 4.40 persen dari luas areal panen nasional (BPS SulSel, 2007). Meningkatnya intensifikasi tanaman pangan mengakibatkan peningkatan produksi limbah tanaman pangan yang dapat digunakan sebagai sumber pakan ruminansia.

Dalam rangka optimalisasi pemanfaatan limbah tanaman pangan sebagai pakan ruminansia di Sulawesi Selatan, diperlukan berbagai upaya pendekatan dan program secara holistik. Program yang dilakukan berangkat dari analisis yang mendalam tentang berbagai faktor yang berpengaruh terhadap pemanfaatan limbah tanaman pangan sebagai pakan. Untuk itu penelitian bertujuan untuk merumuskan strategi pemanfaatan limbah tanaman pangan sebagai sumber pakan ternak ruminansia di Sulawesi Selatan.

\section{METODE PENELITIAN}

\section{Jenis dan Sumber Data}

Dalam penelitian ini digunakan data primer dan data sekunder. Data primer diperoleh dari pakar/unsur pelaku (stakeholder) bidang peternakan yang terkait dengan penelitian ini. Unsur pelaku mewakili berbagai unsur yaitu birokrat/Dinas Peternakan, praktisi (peternak/pengusaha), dan akademisi atau peneliti (dosen perguruan tinggi dan peneliti lembaga litbang). Data primer diperoleh dengan wawancara menggunakan kuesioner dan focus group discussion. Di samping itu dilakukan pula wawancara secara mendalam (indepth $s t u d y$ ) kepada beberapa informan kunci. Data sekunder diperoleh dari instansi terkait dan berbagai sumber kepustakaan yang relevan dengan penelitian ini.

\section{Pengolahan Data}

Data yang diperoleh untuk perumusan strategi adalah data kualitatif dan kuantitatif yang kemudian diolah dan dianalisis dengan menggunakan metode pengolahan data yaitu (a) analisis SWOT, digunakan untuk menganalisis strategi pemanfaatan limbah tanaman pangan sebagai sumber pakan ternak ruminansia di Sulawesi Selatan, dengan menggunakan matriks sebagai alat analisisnya (David, 2001), (b) Analytical Hierarchy Process (AHP) digunakan dalam mengidentifikasi dan melakukan pembobotan terhadap faktor-faktor eksternal dan internal yang terkait dengan pemanfaatan limbah tanaman pangan sebagai sumber pakan ternak ruminansia. Penyelesaian AHP dilakukan dengan menggunakan Criterium Decision Plus (Saaty, 1993; Marimin, 2004)

\section{Teknik Perumusan Strategi}

Metode perumusan strategi pemanfaatan limbah tanaman pangan sebagai sumber pakan ternak ruminansia di Sulawesi Selatan, mengacu kepada tahapan-tahapan teknik perumusan strategi (analisis SWOT) yang 
nansia di Sulawesi Selatan. Elemen kunci terdiri atas beberapa sub elemen variabel kunci seperti dirangkum dalam Gambar 2.

Gambar 2 menunjukkan pemanfaatan limbah tanaman pangan sebagai sumberpakan ternak ruminansia di Sulawesi Selatan dibutuhkan sarana prasarana pengangkutan dan penyimpanan limbah, permodalan untuk peternak, sarana penerapan teknologi pakan, adanya jaminan keamanan beternak, serta kebijakan pemerintah. Dalam pemanfaatan limbah sebagai pakan ditemui kendala antara lain kebiasaan petani membakar jerami, limbah yang tersedia bersifat musiman, dan usaha ternak masih menjadi usaha sambilan.

Beberapa lembaga pelaku yang terlibat dalam upaya pemanfaatan limbah tanaman pangan sebagai pakan ternak ruminansia adalah kelompok tani, koperasi dan usaha kecil menengah, lembaga keuangan, pemerintah, perguruan tinggi, serta organisasi pengusaha peternakan. Di sisi lain, masyarakat yang dapat terpengaruhi adalah petani peternak, pemerintah daerah, pengusaha, manajemen koperasi dan usaha kecil menengah, serta pasar domestik.

Tolak ukur keberhasilan pemanfaatan limbah tanaman pangan sebagai pakan adalah limbah tanaman pangan dapat dimanfaatkan secara optimal. Pemanfaatan limbah sebagai pakan dilakukan penerapan teknologi secara berkesinambungan dengan sistem pemeliharaan ternak yang intensif dan peningkatan skala usaha ternak, yang pada gilirannya akan meningkatkan pendapatan peternak.

\section{KESIMPULAN}

Strategi yang menjadi prioritas dalam pemanfaatan limbah tanaman pangan sebagai sumber pakan ternak ruminansia di Sulawesi Selatan yaitu: (1) pengembangan kawasan pola integrasi sapi potong dengan padi dan jagung, (2) optimalisasi penerapan teknologi pakan limbah tanaman pangan melalui pemberdayaan masyarakat pola partisipatif, (3) membangun industri pakan berbasis bahan baku sumberdaya limbah tanaman pangan, (4) pengembangan sarana alat pengangkutan dan tempat penyimpanan limbah tanaman pangan di pedesaan, dan (5) Penyediaan modal usaha dari pemerintah dan lembaga keuangan melalui kerjasama dengan kelembagaan peternak (kelompok, koperasi).

Lima strategi prioritas seperti disebutkan di atas, disarankan dalam pelaksanaannya di perlukan adanya analisis implikasi strategi yang menjadi arah dan pedoman dalam pelaksanaannya. Implikasi strategi mencakup masalah yang dihadapi, solusi atau pemecahan masalah, program yang harus dilakukan, pelaksana atau unsur yang terlibat dalam rangka mencapai strategi yang dituangkan dalam bentuk program implementasi dalam rangka pengembangan ternak ruminansia di Sulawesi Selatan.

\section{DAFTAR PUSTAKA}

Badan Pusat Statistik. 2007. Statistik Indonesia 2006. Jakarta: Badan Pusat Statistik.

Badan Pusat Statistik Sulsel. 2007. Sulawesi Selatan dalam Angka 2006. Makassar: Badan Pusat Statistik Provinsi Sulawesi Selatan.

Badan Pusat Statistik Sulsel. 2004. Sulawesi Selatan dalam Angka 2003. Makassar: Badan Pusat Statistik Provinsi Sulawesi Selatan.

David, F.R. 2001. Strategic Management: 
Concepts and Cases. 8th ed. New Jersey: Prentice-Hall, Inc.

Dinas Peternakan Sulawesi Selatan. 2004. Statistik Peternakan Tahun 2003. Makassar: Dinas Peternakan Provinsi Sulawesi Selatan.

Dinas Peternakan Sulawesi Selatan. 2001. Rencana Strategik Pembangunan Peternakan Provinsi Sulawesi Selatan (20012005). Makassar: Dinas Peternakan Provinsi Sulawesi Selatan.

Marimin. 2004. Teknik dan Aplikasi Pengambilan Keputusan Kriteria Majemuk. Jakarta: Grasindo.

Saaty, T.L. 1993. Pengambilan Keputusan Bagi Para Pemimpin. Jakarta: PT Pustaka Binaman Pressindo.

Sajimin, Kompiang IP, Supriyati, Lugiyo. 2000. Pengaruh Pemberian Berbagai Cara dan Dosis Bacillus Sp terhadap Produktivitas dan Kulaitas Rumput Panicum Maximum. Prosiding Seminar Nasional Peternakan dan Veteriner. Bogor 18-19 September 2000. Bogor: Puslitbang Peternakan Departemen Pertanian. hlm 359-365.
Syamsu, J.A. 2007. Karakteristik Pemanfaatan Limbah Tanaman Pangan sebagai Pakan Ternak Ruminansia pada Peternakan Rakyat di Sulawesi Selatan. Prosiding Seminar Nasional Asosiasi Ahli Nutrisi dan Pakan Indonesia (AINI) VI. Kerjasama Bagian Nutrisi dan Makanan Ternak Fak. Peternakan UGM Yogyakarta dan AINI. Yogyakarta 26-27 Juli 2007.

Syamsu, J.A., L.A. Sofyan, K. Mudikdjo, E.G. Sa'id, dan E.B. Laconi. 2005. Analisis Potensi Limbah Tanaman Pangan sebagai Sumber Pakan Ternak Ruminansia di Sulawesi Selatan. Jurnal Ilmiah Ilmu-ilmu Peternakan. Vol 8 (4): 291-301.

Syamsu, J.A., L.A.Sofyan, K.Mudikdjo dan E. Gumbira Sa'id. 2003. Daya dukung limbah pertanian sebagai sumber pakan ternak ruminansia di Indonesia. Wartazoa $13(1)$ : 30-37

Syamsu, J.A dan M. Achmad. 2002. Keunggulan kompetitif wilayah berdasarkan Sumberdaya Pakan untuk Pengembangan Ternak Ruminansia di Sulawesi Selatan. Jurnal Agribisnis 6 (2): 11-19. 


\title{
PEDOMAN PENULISAN \\ JURNAL EKONOMI PEMBANGUNAN FAKULTAS EKONOMI UNIVERSITAS MUHAMMADIYAH SURAKARTA
}

Terbit: 2 kali dalam setahun pada bulan Juni dan Desember

\author{
Akreditasi Jurnal: \\ KEPUTUSAN DIREKTUR JENDERAL PENDIDIKAN TINGGI \\ KEMENTERIAN PENDIDIKAN NASIONAL NOMOR: 51/DIKTI/Kep./2010 \\ (masa berlaku Juni 2010 s.d Juni 2013)
}

1. Artikel ditulis dengan bahasa Indonesia atau bahasa Inggris dalam bidang kajian masalah ekonomi dan pembangunan.

2. Substansi artikel diharapkan sejalan dengan Panduan Akreditasi Berkala Ilmiah 2006, yang diterbitkan Direktorat Penelitian dan Pengabdian kepada Masyarakat (DP2M) Direktorat Jenderal Pendidikan Tinggi Republik Indonesia).

3. Artikel ditulis dengan kaidah tata bahasa Inggris ataupun bahasa Indonesia yang baik dan benar.

4. Sistematika Penulisan

Sistematika penjenjangan atau peringkat judul artikel dan bagian-bagiannya dilakukan dengan cara berikut:

(1) Judul ditulis dengan huruf besar semua, di bagian tengah atas pada halaman pertama

(2) Sub Bab Peringkat 1 ditulis dengan huruf pertama besar semua di tengah/center

(3) Sub Bab Peringkat 2 ditulis dengan huruf besar-kecil rata tepi kiri

- Sistematika artikel hasil penelitian adalah: judul; nama penulis (tanpa gelar akademik); nama dan alamat institusi, alamat e-mail penulis, abstrak (maksimum 150 kata) yang berisi tujuan, metode, dan hasil penelitian; kata kunci (4-5 kata kunci); pendahuluan (tanpa ada subjudul) yang berisi latar belakang, sedikit tinjauan pustaka, dan tujuan penelitian; metode; hasil penelitian dan pembahasan; kesimpulan; daftar rujukan (hanya memuat sumber-sumber yang dirujuk).

\section{JUDUL UTAMA:}

\section{Sub Judul}

Penulis $1^{1}$ dan Penulis $2^{2}$

${ }^{1}$ Nama instansi/lembaga Penulis 1

Alamat lengkap instansi penulis, nomor telepon instansi penulis

${ }^{2}$ Nama instansi/lembaga Penulis 2

Alamat lengkap instansi penulis, nomor telepon instansi penulis

(jika nama instansi penulis 1 dan 2 sama, cukup ditulis satu saja)

E-mail penulis 1 dan 2:

Abstrak: Abstrak dalam bahasa Indonesia (125 - 150 kata)

Kata kunci: 4 - 5 katal frase

Abstract: Abstract in english (125 - 150 words)

Keywords: $4-5$ words/ phrase

\section{PENDAHULUAN}

(berisi latar belakang, sekilas tinjauan pustaka, dan tujuan penelitian, yang dimasukkan dalam paragraf paragraf bukan dalam bentuk subbab)

METODE PENELITIAN

Subbab

Subbab

...

\section{HASIL ANALISIS DAN PEMBAHASAN}

Pedoman Penulisan Jurnal Ekonomi Pembangunan FE Universitas Muhammadiyah Surakarta 


\title{
Subbab
}

\section{KESIMPULAN \\ DAFTAR PUSTAKA}

- Sistematika artikel hasil pemikiran adalah: judul; nama penulis (tanpa gelar akademik); nama dan alamat institusi, alamat e-mail penulis, abstrak (maksimum 150 kata); kata-kata kunci (4-5 kata kunci); pendahuluan (tanpa ada subjudul) yang berisi latar belakang dan tujuan atau ruang lingkup tulisan; bahasan utama (dapat dibagi ke dalam beberapa sub-judul); penutup atau kesimpulan; daftar rujukan (hanya memuat sumber-sumber yang dirujuk).

\section{JUDUL UTAMA: \\ Sub Judul}

Penulis $1^{1}$ dan Penulis $2^{2}$

${ }^{1}$ Nama instansi/lembaga Penulis 1

Alamat lengkap instansi penulis, nomor telepon instansi penulis

${ }^{2}$ Nama instansi/lembaga Penulis 2

Alamat lengkap instansi penulis, nomor telepon instansi penulis

(jika nama instansi penulis 1 dan 2 sama, cukup ditulis satu saja)

E-mail penulis 1 dan 2 :

\author{
Abstrak: Abstrak dalam bahasa Indonesia (125--150 kata) \\ Kata kunci: 4 - 5 katal frase \\ Abstract: Abstract in english (125 - 150 words) \\ Keywords: $4-5$ words/ phrase

\section{PENDAHULUAN PEMBAHASAN \\ KESIMPULAN} \\ DAFTAR PUSTAKA
}

5. Artikel diketik pada kertas kwarto berkualitas baik. Dibuat sesingkat mungkin sesuai dengan subyek dan metode penelitian (bila naskah tersebut ringkasan penelitian), biasanya 20-25 halaman dengan spasi satu, untuk kutipan paragraf langsung diindent (tidak termasuk daftar pustaka).

6. Marjin atas, bawah, dan samping harus dibuat paling tidak satu inci.

7. Abstrak, ditulis satu paragraf sebelum isi naskah. Abstrak dalam dua bahasa yaitu bahasa Indonesia dan bahasa Inggris. Abstrak tidak memuat uraian matematis, dan mencakup esensi utuh penelitian, metode dan pentingnya temuan dan saran atau kontribusi penelitian.

8. $\quad$ a. Penulisan numbering diintegrasikan dalam paragraf, contohnya:

Tujuan dilakukannya penelitian ini adalah: (1) Untuk mengetahui apakah CSR berpengaruh positif terhadap nilai perusahaan, (2) Untuk mengetahui apakah persentase kepemilikan manajemen berperan sebagai variabel moderating dalam hubungan antara CSR dengan nilai perusahaan, dan (3) Untuk mengetahui apakah tipe industri berperan sebagai variabel moderating dalam hubungan antara CSR dengan nilai perusahaan?

b. Penulisan bullet juga diintegrasikan dalam paragraf dengan menggunakan tanda koma pada antarkata/kalimat tanpa bullet.

9. Tabel dan gambar, untuk tabel dan gambar (grafik) sebagai lampiran dicantumkan pada halaman sesudah teks. Sedangkan tabel atau gambar baik di dalam naskah maupun bukan harus diberi nomor urut.

- Tabel atau gambar harus disertai judul. Judul tabel diletakkan di atas tabel sedangkan judul gambar diletakkan di bawah gambar.

Pedoman Penulisan Jurnal Ekonomi Pembangunan FE Universitas Muhammadiyah Surakarta 
- Sumber acuan tabel atau gambar dicantumkan di bawah tabel atau gambar.

- Garis tabel yang dimunculkan hanya pada bagian header dan garis bagian paling bawah tabel sedangkan untuk garis-garis vertikal pemisah kolom tidak dimunculkan.

Contoh: Tabel

Tabel 1. Bentuk-bentuk Mobilitas Penduduk

\begin{tabular}{llll}
\hline No & Bentuk Mobilitas & Batas Wilayah & Batas Waktu \\
\hline 1. & Ulang-alik (commuting) & Dukuh (dusun) & 6 jam atau lebih dan kembali pada hari yang sama \\
2. & Menginap/mondok di daerah tujuan & Dukuh (dusun) & Lebih dari satu hari tetapi kurang dari 6 bulan \\
3. & Permanen/menetap di daerah tujuan & Dukuh (dusun) & 6 bulan atau lebih menetap di daerah tujuan \\
\hline
\end{tabular}

Sumber: Ida Bagoes, 2000

\section{Contoh: Gambar}

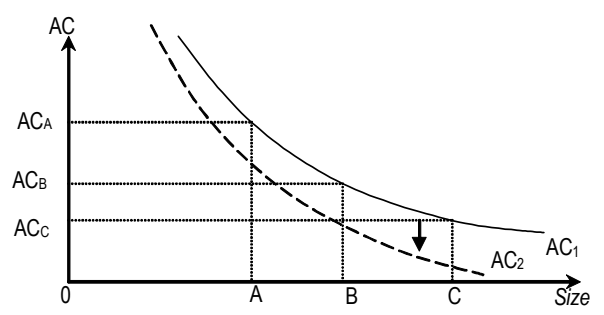

Sumber: Saunders (1997: 291)

Gambar 2. Dampak Peningkatan Teknologi

10. Cara penulisan rumus, Persamaan-persamaan yang digunakan disusun pada baris terpisah dan diberi nomor secara berurutan dalam parentheses (justify) dan diletakkan pada margin kanan sejajar dengan baris tersebut. Contoh:

$\mathrm{wt}=\mathrm{f}\left(\mathrm{y}_{\mathrm{t}}, \mathrm{k}_{\mathrm{t}}, \mathrm{w}_{\mathrm{t}-1}\right)$

11. Keterangan Rumus ditulis dalam satu paragraf tanpa menggunakan simbol sama dengan (=), masingmasing keterangan notasi rumus dipisahkan dengan koma. Contoh:

Dimana $\mathbf{w}$ adalah upah nominal, $\mathbf{y t}$ adalah produktivitas pekerja, kt adalah intensitas modal, $\mathbf{w}_{\mathbf{t}-\mathbf{1}}$ adalah tingkat upah periode sebelumnya.

12. Perujukan sumber acuan di dalam teks dengan menggunakan nama akhir dan tahun. Kemudian bila merujuk pada halaman tertentu, penyebutan halaman setelah penyebutan tahun dengan dipisah titik dua. Untuk karya terjemahan dilakukan dengan cara menyebutkan nama pengarang aslinya.

Contoh:

- Yuni (2008: 23) memandang bahwa .....

- Fatimah dan Daryono (1997) menunjukkan adanya ....

- Didit dkk (2007) berkesimpulan bahwa....

- Untuk meningkatkan perekonomi daerah .... (Yuni, Triyono, dan Agung Riyardi, 2009).

- Maya (2009) berpendapat bahwa ....

13. Setiap kutipan, baik langsung maupun tidak langsung, harus diikuti sumbernya (lihat poin no. 10) dan dicantumkan juga dalam daftar pustaka. Contoh:

Di dalam paragraf isi tercantum kutipan dari: Buiter (2007:15) berpendapat bahwa...

Maka dalam daftar pustaka harus ada sumber referensinya seperti berikut:

Buiter, W. H., (2002). The Fiscal Theory of the Price Level: A Critique, Economic Journal, 112(127): 459-480.

Pedoman Penulisan Jurnal Ekonomi Pembangunan FE Universitas Muhammadiyah Surakarta 
14. Sedapat mungkin pustaka-pustaka yang dijadikan rujukan adalah pustaka yang diterbitkan 10 tahun terakhir dan diutamakan dari jurnal ilmiah.

15. Unsur yang ditulis dalam daftar pustaka secara berturut-turut meliputi: (1) nama akhir pengarang, nama awal, nama tengah, tanpa gelar akademik, (2) tahun penerbitan, (3) judul termasuk subjudul, (4) tempat penerbitan, (5) nama penerbit.

Contoh cara penulisan:

a. Format rujukan dari buku: Nama pengarang, (tahun), Judul Buku, edisi, Kota penerbit, Nama penerbit. Jika penulis sebagai editor tunggal, ditulis (Ed.) di belakang namanya. Ditulis (Eds.) jika editornya lebih dari satu orang. Kemudian bila pengarang lebih dari tiga orang, dituliskan nama pengarang pertama dan yang lain disingkat 'dkk' (pengarang domestik) atau 'et.al.' (pengarang asing).

Enders, W., (2004), Applied Econometric Time Series, Second edition, New York: John Wiley \& Sony Inc. Purnomo, Didit (Ed.). (2005). The Role of Macroeconomic Factors in Growth. Surakarta: Penerbit Muhamadiyah University Press.

b. Format rujukan dari artikel dalam buku ditulis: Nama editor (Ed.), (tahun), Judul tulisan/karangan. Judul buku, hlm atau pp., kota penerbit: nama penerbit

Daryono (Ed.). (2005). Concept of Fiscal Decentralization and Worldwide Overview (hlm. 12-25). Surakarta: Penerbit Muhammadiyah University Press.

c. Format rujukan dari artikel dalam jurnal/majalah/koran: Nama pengarang (tahun). judul tulisan/ karangan. Nama jurnal/majalah/koran, hlm atau pp., volume (nomor), halaman. Jika rujukan koran tanpa penulis, nama koran ditulis diawal.

Rodden, J., (2002). The dilemma of Fiscal Federalism: Grants and Fiscal Performance arround the World. American Journal of Political Science, 46 (3): 670-687.

Triyono (2008). Perimbangan Keuangan Pusat dan Daerah Sebagai Pelaksanaan Desentralisasi Fiskal Efek. Warta Ekonomi, Vol. 4, Agustus: 46-48.

Haryanto, S., (2007, 13 November). Desentralisasi Fiskal dan Pembangunan Ekonomi. Harian Jakarta, hlm.4.

Harian Jogjakarta, (2007, 1 April). Hubungan Keuangan Pusat-Daerah di Indonesia. hlm. 4.

d. Format rujukan dari internet, tanggal akses dicantumkan.

Setyowati, E.,. Keuangan Publik dan Sistem Harga. http://www.ekonomipublik.com/akt/pdf/akt452.pdf.

Diakses tanggal 27 Mei 2009.

\section{Pengiriman Artikel}

1. Artikel dikirimkan sebanyak 2 eksemplar hardcopy, dan softcopy berupa file. File bisa dikirim melalui email jepums@yahoo.co.id atau dalam media cd.

2. Artikel yang dikirim wajib dilampiri biodata ringkas pendidikan termasuk catatan riwayat karya-karya ilmiah sebelumnya yang pernah dipublikasikan, insitusi dan alamatnya, nomor telpon kontak atau e-mail penulis.

3. Penulis yang menyerahkan artikelnya kepada editor atau penerbit, harus menjamin bahwa naskah yang diajukan tidak melanggar hak cipta, belum dipublikasikan atau telah diterima untuk dipublikasi oleh jurnal lainnya.

4. Kepastian pemuatan atau penolakan naskah akan diberitahukan secara tertulis. Penulis yang artikelnya dimuat mendapatkan jurnal tersebut. Artikel yang tidak dimuat tidak akan dikembalikan.

\section{Alamat Redaksi Jurnal Ekonomi Pembangunan Fakultas Ekonomi Universitas Muhammadiyah Surakarta: \\ Redaksi Jurnal Ekonomi Pembangunan Fakultas Ekonomi Universitas Muhammadiyah Surakarta Jalan A. Yani Tromol Pos I Pabelan SURAKARTA 57102 Telp. 0271-717417 psw 229}

Pedoman Penulisan Jurnal Ekonomi Pembangunan FE Universitas Muhammadiyah Surakarta 
TENTANG JURNAL:

\title{
JURNAL EKONOMI PEMBANGUNAN
}

Kajian Masalah Ekonomi dan Pembangunan

ISSN 1411- 6081

\author{
Pimpinan Redaksi \\ Didit Purnomo
}

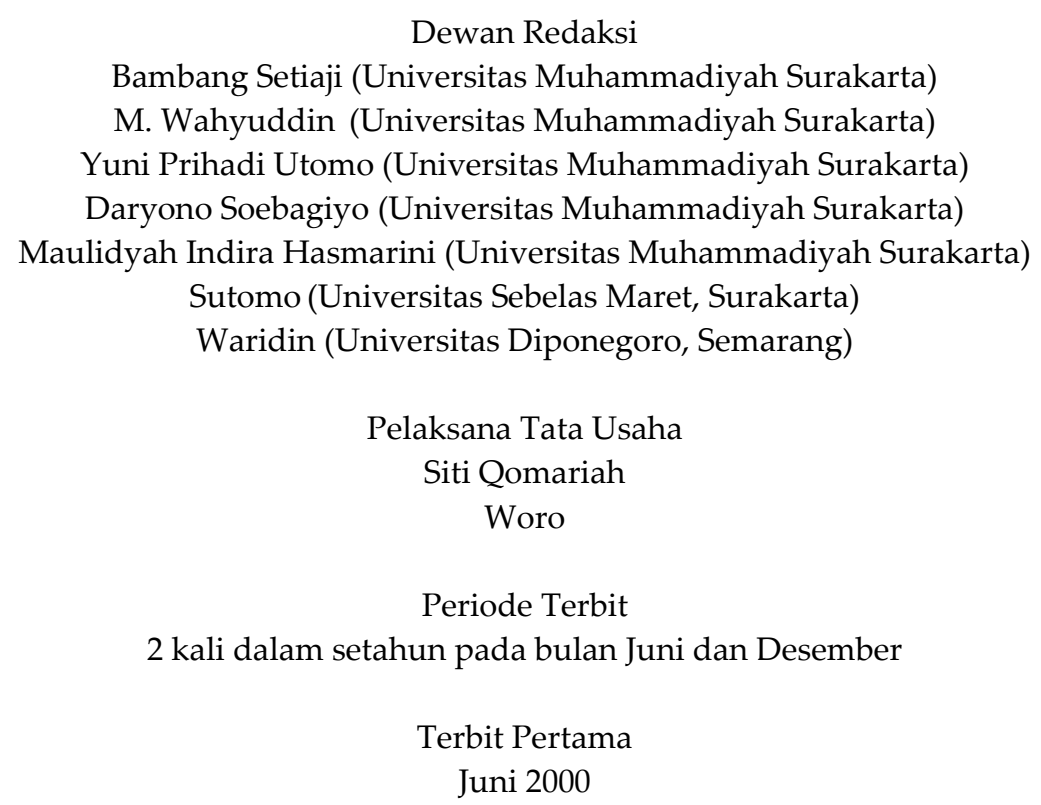

Jurnal EKONOMI PEMBANGUNAN merupakan jurnal ilmiah yang berisikan hasil penelitian dan kajian teoritis mengenai masalah-masalah ekonomi dan pembangunan, khususnya di Indonesia. Diterbitkan oleh Balai Penelitian dan Pengembangan Ekonomi Fakultas Ekonomi Universitas Muhammadiyah Surakarta.

Redaksi menerima sumbangan tulisan yang belum pernah diterbitkan atau dalam proses terbit oleh media lain. Naskah diketik di atas kertas HVS kuarto spasi satu sepanjang lebih kurang 20-25 halaman, dengan format seperti tercantum pada prasyarat naskah jurnal EKONOMI PEMBANGUNAN di halaman belakang. Naskah yang masuk akan dievaluasi dan disunting untuk keseragaman format dan tata cara lainnya.

Alamat Penyunting dan Tata Usaha: Subag Tata Usaha Fakultas Ekonomi Universitas Muhammadiyah Surakarta, Jl. A. Yani, Tromol Pos 1, Pabelan, Surakarta 57102; Telpon (0271) 717417 psw 229,

E-mail: jepums@yahoo.co.id

Website: http://www.ums.ac.id atau http://www.paradejurnal.wordpress.com

Simak informasi jurnal: http://www.paradejurnal.wordpress.com

Admin: Mirat Sidharta. SE

Pedoman Penulisan Jurnal Ekonomi Pembangunan FE Universitas Muhammadiyah Surakarta 